\section{Names: a historical or political perspective?}

Sir - I have two questions in response to Rognes's Correspondence (Nature 417, 379; 2002). First, has most of his research work been done before or after June 1967? The "occupied territories" have been within Israel's borders since that date. If the major piece of research was performed after 1967, surely the territories should be referred to by their current names? Would anyone in the scientific community nowadays call India a part of the 'British Dominion', or place Ukraine in the 'USSR'? Would anyone use the name 'Rhodesia' when referring to Zimbabwe or 'Ceylon' instead of Sri Lanka?

As with any scientific nomenclature, a scientist is required by a journal to use the current names of territories, regardless of his or her politics. It may be useful to add comments regarding historical names if they are relevant to the research described.

Second is the issue of showing some respect to the publisher's country. If you know that certain names are a sensitive issue in certain countries, and you do not wish to take sides in a political debate local to the area, why not use the terms that are used by the country concerned and by most of the world? I do not think Nature's publishers in the United Kingdom would be happy to review manuscripts referring to the Falkland Islands as the 'Malvinas'.

\section{Sharona Even-Ram}

National Institute of Dental and Craniofacial Research, National Institutes of Health, 30 Convent Drive, Bethesda, Maryland 20892, USA

Nature allows contributors to use their own choice of name (if in standard use) for the region from which they are writing. This holds for the Falkland Islands/ Malvinas as for other regions of the world, such as Taiwan - Editor, Correspondence

\section{Only vital need justifies primate experiments}

Sir - In your recent Opinion article on when experiments with non-human primates can be justified (Nature 417, 684-687, 2002), a relevant perspective can be found in US constitutional law. A non-human primate can be regarded as belonging to the 'quasi-person' class originally used in 1865 to define AfricanAmericans, who were not accorded full constitutional personhood in law, but were entitled to some natural rights under the US constitution, including that of selfinterest (see R. M. Lebovitz, St Thomas Law Review, 14, 561-600; 2002). But does this mean that primates are entitled constitutionally to be free from the physical abuse produced by experimentation?

No constitutional right is absolute, but there must be an important and persuasive reason for abrogating it. In the United States, a person's so-called 'liberty interest' is a fundamental constitutional right, yet the government can infringe upon it when the circumstances are important enough. A famous example is an early twentieth century case in which an adult man refused to be vaccinated against smallpox, despite a Massachusetts state law requiring it. The case made its way to the US Supreme Court, where the justices wrote that constitutional rights are not unencumbered, but may be infringed when necessary for the good of the community, including for reasons of public safety to protect the population from a disease epidemic (Jacobson vs Massachusetts, 197 US 11; 1905).

Using the same rationale, it can be argued that, although most animal experimentation is not significant enough to warrant violating a primate's right of self-interest, some experimentation may meet this high standard. For instance, research on a particular vaccine may be important enough as a societal concern to excuse intrusion on the animal's right of self-interest. We must carefully scrutinize the goals of experimentation to determine when it justifies extinguishing a US animal's constitutional right of self-interest.

\section{Richard M. Lebovitz}

Interdisciplinary Bioscience PhD Program, George Mason University, 4400 University Drive, Fairfax, Virginia 22030-4444, USA

\section{Little funding to develop non-animal testing}

Sir - Your News Feature "The great primate debate" (Nature 417, 684-687; 2002) did not discuss the potential of in vitro and clinical studies to replace many primate experiments in drug development, neuroscience and AIDS research. Nonanimal methods can — and should — be supported by all sides of the debate. While verbal support is often forthcoming, resources to develop such alternative methods are not. Despite its responsibility under European legislation, the British government's budget for alternatives is sub-divided into different areas, with the intention that developing replacements for animal experiments should receive about $\mathfrak{£} 56,000$ (US $\$ 85,500$ ) a year — barely enough to fund one research project. Gill Langley

Dr Hadwen Trust for Humane Research,

84 a Tilehouse Street, Hitchin, Herts SG5 2DY, UK

\title{
Are results of primate research worth the suffering it causes?
}

\section{Researchers must be honest about methods and goals.}

Sir - Your Opinion article ("Distasteful but necessary", Nature 417, 673; 2002)

does not explore in depth the morality of experimenting on non-human primates. You claim that the issue is "simple", that "potential benefits must be weighed against the suffering caused". But nobody would apply a cost-benefit test to experimenting on people against their will. What is the difference? Your argument can only be that non-human primates are one sort of primate and we are another, so it is acceptable for us to cause them pain.

That approach cannot withstand any intellectual scrutiny. Primates are just as capable of suffering as we are. Suffering, and its avoidance, lies at the heart of all moral philosophy. If it is wrong to cause suffering to people deliberately whatever the benefits to others - it must also be wrong to do so to other primates.

You also say that it is time to inform public opinion about primate research. I agree. But that has to mean full information, not simply such information as researchers find it convenient to disclose. It should not take undercover investigations, such as that recently carried out by the British Union for the Abolition of Vivisection (BUAV) into primate research at Cambridge University, to reveal the extent of suffering involved (caused both by the experiments and the housing conditions) and to raise serious questions about the usefulness of the research.

BUAV is calling for an inquiry into primate research in the United Kingdom independent of the Home Office, which has once again shown, in the Cambridge case, that it is not up to its regulatory task. Will primate researchers support BUAV in this call? If not, it will only strengthen the growing perception that researchers and government alike would prefer to keep the public in the dark.

Michelle Thew

British Union for the Abolition of Vivisection, 16a Crane Grove, London N7 8NN, UK 